\title{
WAT HEBBEN WIJ VAN DE NEDERLANDSCHE BANKWET TE DENKEN EN TE WACHTEN?
}

\author{
Mr. P. VerdoRen, de Verhouding van den \\ Slaat tot het Bankwezen. Utrecht, $\mathrm{Ke}-$ \\ mink en Zoon, 1864.
}

Er behoort veel moed toe, om, weinige maanden nadat de wet, houdende voorzieningen omtrent de Nederlandsche Bank (22 Dec. 1863) is uitgevaardigd, aan het publiek een betoog in ruim 600 bladzijden te komen anbieden, in het voordeel der vrijheid van circulatiebanken. Alleen een vast vertrouwen op de deugd zijner zaak kon den heer $V$. aansporen, om een zóó gewaagden strijd tegen de kracht der traagheid aan te gaan. Immers, hoezeer de letter onzer Bankwet het beginsel van concurrentie niet uitsluit, hare onmiskenbare strekking is, dat niet vóór $\mathrm{A}_{0} .1889$ de noodzakelijkheid van eene nieuwe bemoeijing des wetgerers besta; de wet, en de tot hare uitroering gemaakte reglementen, zijn er op ingerigt om het bankwezen hier te lande, gedurende 25 jaren, onveranderd te behouden, zooals het nu is georganiseerd. Welke katastrophen of onvoorziene omstandigheden gedurende dat tijdvak tot nieuwe maatregelen mogen nopen, kan niemand vooruitzien; maar bezwaarlijk zal een enkel betoog, met hoeveel kennis van zaken ook gesteld, te weeg brengen, dat nu reeds een nieuwe greep worde gedaan in hetgeen eerst onlangs geregeld is. Sedert iets minder dan één jaar loopt de wagen in het spoor, door de Bankwet aangewezen; er zou meer kracht en invloed noodig zijn, dan meestal van een degelijk, wetenschappelijk boek te verwachten is, om hem uit dat spoor te ligten. Dit is het wat in deze zaak de bijna onverwinbare "kracht der traagheid" mag worden genoemd.

Ref. is intusschen, met den heer V., voorstander van bankvrijheid, in den zin van concurrentie ook tusschen circulatie-banken, mits voor de oprigting en het beheer dezer instellingen vóóraf goede wettelijke regelen zijn gesteld; hij moet het dus betreuren, dat ruim de helft van het aangekondigde werk (bl. 1 tot 332), die 
blijkbaar geschreven is vór de behandeling der Bankwet in de Staten-Generaal, niet vóór die discussie het licht heeft gezien. Of die tijdige uitgave eenige verandering in de beslissing der wetgevende magt zoude hebben te weeg gebragt, is ten eenenmale onzeker. Maar zij zoude de verdedigers van het privilegie en van de z. g. éénheid van circulatie misschien meer uit hunne verschansingen hebben gelokt, en hen hebben genoodzaakt, de uitgifte van bankbilletten meer te bespreken in haar onafscheidelijk verband met de andere takken van het bankbedrijf. Zoo als de loop der zaak in 1863 is geweest, heeft men (behalve uit politieke drijfveren) het privilegie aan de Ned. Bank zien verleenen, omdat de opinie der meerderheid, althans in de Kamers, deze drie stellingen als onomstootelijk beschouwde:

a. bankbilletten zijn een surrogaat voor geld; hij die ze uitgeeft, vermeerdert de hoeveelheid van het omloopend betaalmiddel naar willekeur;

b. door wanbestuur en daaruitvolgende wanbetaling eener Bank verliezen de bankbilletten hare waarde, en wordt het publiek, zoowel het handeldrijvende als het niet handeldrijvende, grootelijks benadeeld;

c. ééne geprivilegieerde Bank, onder staatstoezigt, wordt beter bestuurd en levert meer waarborgen op, dan vrije banken, die met elkander mededingen.

Van deze drie stellingen is alleen de tweede eene onbetwistbare warheid; de omvang van het gevreesde nadeel hangt van omstandigheden af, maar de staking van betaling eener bank is altijd eene ramp voor velen.

De eerste stelling daarentegen, de grondslag der currency-theorie, hoewel door verdienstelijke staathuishoudkundigen angenomen, mag hoogst betwistbaar heeten. Op wetenschappelijk terrein schijnt zij het niet te kunnen houden tegen de leer van het crediet, in de laatste jaren door Mac Leod ontwikkeld.

En wat de derde stelling betreft, de verkregene en welbekende resultaten in menig Rijk zijn dáár om hare volkomene onjuistheid aan te toonen.

De verdienste van den heer $V$. is deze, dat hij, om de zaak der bankvrijheid te bepleiten, zich als hoofdrraag heeft gesteld: In welke behoeften zijn de banken in het algemeen geroepen to roorzien? - Ter beautwoording dezer vraag beschouwt hij de oude onderscheiding tusschen deposito-, wissel- en circulatie-banken, als alleen nog maar van historisch belang; alle banken en bankiers 


\section{1}

zijn roor hem handelaars in geld en edele metalen, en tevens in crediet. Van dit standpunt overweegt hij de eischen, die de Staat aan zoodanige handelaars mag en moet stellen. Deze eischen alleen tot de gereede inwisselbaarheid van het bankbillet te beperken, komt hem kortzigtig voor; die uit te strekken tot eene onfeilbare gewisheid bij elke crediet-verleening, acht hij onbestaanbarr; als de beste waarborgen erkent hij: concurrentie, mits tusschen personen die iets te verliezen hebben, verpligte openbaarheid, en straffen tegen alle handelingen te kwader trouw gepleegd.

Doorloopen wij kortelijk den weg, langs welken de Schr., met groote uitvoerigheid, tot deze uitkomsten geraakt is.

Nadat in de inleiding (bl. 1-25) de vrijheid van bedrijf in het algemeen geprezen, en de vraag onderzocht is, waarom vele voorstanders van die vrijheid, haar toch niet in het bankwezen willen huldigen, wordt in Hoofdstuk I (bl. 26-77) het ,wezen van het bankbillet en zijne verhouding tot de overige circulatiemiddelen" behandeld. Het bankbillet is niet, uit zijnen aard, papieren geld, hoezeer er landen bestaan, zooals b.v. Oostenrijk, alwaar de bankbilletten door een ieder in betaling moeten worden aangenomen, en andere landen, zooals b.v. Nederland, alwaar het papieren geld (de muntbilletten) voortdurend inwisselbaar is; het onderscheid tusschen bankbilletten en papieren geld bestaat hierin, dat de uitgifte der eerste berust op de vrijwillige daad van dengene, die ze van de Bank ontvangt, die van het tweede op het staatsgezag. - Het bankpapier vertegenwoordigt ook niet, zooals door sommige schrijvers beweerd is, eene bepaalde hoeveelheid goud of zilver in de kelders der Bank, even als een ceêl, warrant of cognoscement eene bepaalde partij goederen in een entrepôt, pakhuis of schip vertegenwoordigt. Het bankbillet is eene belofte van betaling van de Bank an toonder zonder termijn; hij die het in betaling aanneemt, onverschillig of hij de eerste of de latere houder is, verleent aan de Bank een crediet, en wel renteloos, maar telken dage opzegbaar. Daaruit volgt echter niet, dat, als die houder het bankbillet uitgeeft of daarvoor geldspecie komt vragen, hij ophoudt vertrouwen in de Bank te stellen. Dit heeft alleen in buitengewone gevallen plaats, wanneer een zoogenaamde run upon the bank voorkomt. Gewoonlijk heeft de uitgifte of inwisseling van een bankbillet geen ander doel, dan om daarvoor een ander geldswaardig voorwerp of ook eene andere in crediet bestaande waarde te verkrijgen. Niettemin wordt door iedere inwisseling van een billet bij de Bank eene crediet-operatie besloten, en eene schuld gedelgd, 
hetzij daarbij specie wordt uitbetaald of eene nieuwe crediet-verleening plaats heeft.

Dit alles heeft het bankbillet gemeen met het boekcrediet van iedere Bank; alleen de wijze van overdragt is verschillend; maar in het wezen der zaals js de verhouding tusschen de Bank en den persoon, die haar crediet verleent, dezelfde. Even als an ieder boekcrediet, zoo ligt dan ook aan de uitgifte van ieder bankbillet eene transactie ten grondslag, en ligt het even zoozeer buiten de magt der Bank, meer bankbilletten in omloop te houden, dan de behoefte van het publiek vereischt, als het haar mogelijk is, de houders van boekcrediet te beletten, daarover te beschikken, wanneer zij dit wenschen te doen. Ontstaat er slechts een begin van mistrouwen in de Bank, dan zal de neiging van de houders èn van boekcrediet èn van bankbilletten, om betaling te vragen, even groot en weldra onwederstaanbaar worden. - In het breede bespreekt de heer $\mathrm{V}$. bij dit vertoog, de leer der currency, zooals deze tijdens de behandeling der Engelsche bank-wet van 1844, door Robert Peel en lord Overstone werd verkondigd; de vrees, dat eene te groote rrijheid om bankbilletten uit te geven, het algemeene betaalmiddel (geld en bankbilletten) zoude depreciëren, en daardoor de edele metalen uit het land drijpen, deze vrees, door hoe kundige staatslieden ook gekoesterd, is in de oogen van onzen schr. eene hersenschim, door de ondervinding ten eenen male gelogenstraft.

Zeer lezenswaardig is zijn IIe hoofdstuk: ,het bankiersbedrijf en de banken," (bl, 78-165), waarvan de slotsom, zeer in het algemeen, kan worden geformuleerd in de woorden van Richelot (*): "Les banques sont des boutiques ouvertes pour "l'achat des dettes commerciales." - Op de deugdelijkheid der aangekochte inschulden, op de z.g. portefeuille der Bank komt het boven alles aan; dààrop toch berust hoofdzakelijk de zekerheid, die behoort te bestaan, dat de Bank zelve hare verbindtenissen zal naleven; de voorraad gemunt geld en metaal, en de staatsschuldbrieven, waarin een deel van het bankkapitaal belegd wordt, mogen in tijden van krisis tot nood-waarborg strekken, maar verzekeren niet tegen onvoorzigtige operatiën. Uit deze algemeene stellingen wordt teregt het gevolg getrokken, dat de meerdere of mindere soliditeit der handelaars, met wie de Bank in betrekking staat, van grooten invloed moet zijn op de soliditeit der Bank. Bij de

(*) Oute révolution en économie politique, p. 344. Dit werk geeft een zeer duidelijk overzigt der vorderingen, die de staathuishoudkunde aan Mac Leod te danken heeft, 
beoordeeling der handelingen van de Amerikaansche Banken, vergeleken b.v. met de Schotsche en $\mathrm{Z}$ witsersche, moet dit niet uit het oog worden verloren.

In Hoofdstuk III (bl. 166-331) getiteld : „de Banken en de "Wetgeving," is de heer V. aan de kern van het door hem behandelde vraagstuk. Met groote juistheid wordt allereerst, in het belang van een goed bankwezen, aan den wetgever de eisch gesteld van eene goede regeling der faillissementen, en der vennootschappen met beperkte aansprakelijkheid. Het kapitaal, waarmede de naamlooze of commanditaire vennootschap heet te werken, moet werkelijk beschikbaar, en hare statuten moeten waarheid zijn. Als evenwel aan deze vereischten voldaan is, blijft het meest kritieke punt nog over, het stellen nl. van bijzondere regelen voor de banken, of eigenlijk voor diegenen, die zich associëren om het bankbedrijf uit te oefenen. Slechts ééne bepaling verdient daaromtrent onvoorwaardelijke aanbeveling, het is die van publiciteit; zij is tweeledig: de openbaar gemaakte statuten moeten het kapitaal en de soort van operatiën omschrijven, waarmede de Bank zich zal bezig houden, en uit de periodieke staten moet het publiek zich met een oogopslag kunnen overtuigen van den toestand der Bank.

Is daarenboven ook nog een voortdurend toezigt van regeringswege wenschelijk, om de zekerheid te hebben dat de statuten worden nageleefd? Hieromtrent wordt geen beslissend oordeel uitgesproken; maar wel iedere beperking van het getal circulatiebanken, ieder privilegie aan bestaande banken voor de toekomst te geven, afgekeurd. Daar het monopolie van eéne circulatiebank in die landen, waar het bestaat (hoewel historisch op geheel andere gronden ontstaan), bijna uitsluitend wordt verdedigd op grond van bezorgdheid voor overdrevene uitgifte van bankbilletten, zoo gaat de heer $\mathrm{V}$. in bijzonderheden na, welke oorzaken eigenlijk in tijden van handelskrisis aanleiding hebben gegeven tot den val van onderscheidene banken in Groot-Brittannië en Amerika; en dit onderzoek leidt hem tot de uitkomst, dat een overmatig boekcrediet en ondeugdelijke portefeuille veel meer tot die financieele rampen hebben bijgedragen, dan eene overproductie van bankbilletten, welke, zoolang laatstgemelde op vertoon inwisselbaar blijven, zich zelf verbiedt. Eerst dan, wanneer eene bank van de regering het voorregt erlangt, bankbilletten uit to geven, die niet ten allen tijde met muntspecio of metaal behoeven te worden betaald, zoo als van 1797 tot 1819 de Bank van Engeland, en sedert 1848 tot heden de Weener Bank; eerst dan outstaat het geval, dat de andeelhouders dier Bank groote 


\section{4}

voordeelen kunnen behalen op hare crediet-operatiën, ten koste der houders van bankbilletten, die een renteloos kapitaal verstrekken, dat voor het grootste gedeelte in omloop blijft en in hunne handen aan depreciatie bloot stant. (*)

Neemt men het systeem van mededinging tusschen circulatiebanken aan, dan vooral ontstaan voor den wetgever de volgende vragen, die met zorg door den heer V. worden overwogen: Geeft beperkte verantwoordelijkheid der aandeelhouders meer waarborgen aan het publiek dan de onbeperkte, die in de vroegere Engelsche wet verpligtend was? Het oordeel is (zoo wij meenen, teregt,) gunstig voor de beperkte verantwoordelijkheid, mits de Directie afzetbaar en tot de naleving der wet eu statuten, zelfs met strafbepalingen, verbonden zij.

Welke operatiën moet de wetgever aan alle Banken toestaan? Het antwoord (op bl. 282) op deze vraag gegeven, komt vrij wel overéén met den inhoud der Ned. Bankwet, art. 7; behalve dat de Schr. de banken ook wil magtigen tot het verleenen van kascrediet onder persoonlijke borgtogt van twee of meer personen, en tot het nemen van geld à deposito met beding van rentebetaling. Deze laatste soort van operatiën neemt de Schr. zeer in bescherming, vooral tegen de meening der Pruissische en Fransche wetgevers, die haar onbestannbar achten met de gelijktijdige uitgifte van rentelooze schuld in den vorm van bankbilletten en rekening-courantsaldo's. De ondervinding van meer dan eene eeuw in Schotland lromt hem daarbij te hulp. Zoude er echter geen onderscheid moeten worden gemaakt tusschen die Staten, waar bankvrijheid bestaat. en dientengevolge de rente gevende deposito's redelijkerwijze niet kunnen worden verboden, en die welke het maken van bankbilletten als een privilegie voorbehouden? In deze, zoo als Oostenrijk, Frankrijk en Nederland, mag het als een correctief van de onvrijheid der andere crediet-instellingen worden beschouwd, dat de geprivilegiëerde bank, van welke zij uit den aard der zaak afhankelijk worden, niet ook op dit gebied met haar concurreert.

Ook de vraag, of de wet een minimum voor het bedrag van ieder bankbillet behoort aan te nemen? (bij ons $f$ 25) wordt met uitroerigheid behandeld en ontkennend beantwoord, vooral op grond dat, door het betalen met bankbilletten, ook voor kleine sommen,

(*) Door het grootste gedeelte; want, daar de betalingen an eene dergelijke geprivilegiëerde bauk zelve en Han de Staatskassen, in bankbilletten kunnen geschieden, hetft de deprecistie van bankbilletten hare greazen, ook al aijn zij niet inwisselbaar thegen goud on zilser. 
gemakkelijk te maken, het verleenen en het genieten van orediet door de banken wordt bevorderd, en zij dus méér diensten aan het publiek bewrijzen, dan wanneer zij alleen groote billetten uitgeven. Daarenboven leert de ondervinding, dat de billetten van klein bedrag gemiddeld langeren tijd in omloop blijven, dan de groote.

Ten slotte van dit hoofdstuk bespreekt de heer $\nabla$. de maatregelen, die hem wenschelijk voorkomen in het rampspoedige geval, dat eene bank hare betalingen staakt. De bankwetten van eenige Noord-Amerikansche Staten, o. a. New-York, bevatten daarover bepalingen, die hij gedeeltelijk aanprijst. Hij schijnt echter niet te hebben geraadpleegd de belangrijke Bankwet van 25 Februarij 1863 , die thans (met eenige wijzigingen, daarin bij de wet van 3 Junij 1864 gebragt) voor de geheele Vereenigde Staten geldt.

De hoofdbepalingen dezer wet zijn : dat ten bureele van een ambtenaar, Comptroller of the curvency, aan elke bank die aan de vereischten der wet voldoet, worden uitgereikt een door haar verlangd bedrag aan noles for circulation, ten bedrage van 5, 10, 20, 50, 100, 500 en 1000 doll., voorzien van een stempel van staatswege, tot een maximum van $90 \mathrm{pCt}$. der nominale waarde van eene hoeveelheid obligatiën der V. S., welke de Bank vóbraf zal hebben gedeponeerd in handen van den thesaurier der republiek; dat die notes in omloop komen met de handteekeningen der bestuurders van de Bank, die ze heeft angerraagd en uitgeeft; dat iedere Bank voor minstens een derde van haar maatschappelijk kapitaal zoodanige obligatiën moet koopen en deponeren, tot waarborg dat zij hare verpligtingen jegens het publiek zal nakomen; dat alle aldus gewaarborgde notes for circulation bij alle landskantoren à pari worden aangenomen; dat, zoodra eene bank in gebreke blijft een harer notes te betalen in geld, protest van wanbetaling wordt gemaakt, hetgeen ten gevolge heeft dat de Bank, van dien dag af aan, geene andere operatiën mag verrigten en geene betalingen doen, dan het ontvangen en uitkeeren van eigenlijk gezegde dépôts; dat de obligatiën van eene gebrekige Bank worden verkocht tot zoodanig bedrag als noodig is om hare in omloop gebragte notes te betalen, hetgeen dan ook door de schatkist geschiedt; dat iedere Bank altijd aan courant geld (daaronder begrepen opeischbaar papier op de Banken der 9 grootste steden van de Unie) in kas moet hebben $25 \mathrm{pCt}$. van het bedrag harer in omloop zijnde notes en rekeningcourant- of depositorekening-saldo's; dat banken vóór den 1 Januarij 1863 in de V. 8. gevestigd, des verkiezende, zich naar deze wet kunnen inrigten. Het minimum van $25 \mathrm{pCt}$. in oassa is reeds te hoog roorgekomen; 
in 1864 is het alleen behouden voor 16 groote steden; in andere plaatsen kunnen de Banken volstaan met $15 \mathrm{pCt}$, waarvan $\frac{3}{5}$ mag bestaan in balances (opeischbare saldo's) op de Banken in die steden. Deze wet is vooral merkwaardig, als een voorbeeld, hoe de bank-operatiën zich schikken naar den toestand van den handel, van het publiek crediet en van de betaalmiddelen, in plaats van die te beheerschen, en niet minder als eene poging van den wetgever, om zeer strenge voorzorgen te nemen, ja eene volledige voogdij over de bankdirectiën uit te oefenen, en evenwel het beginsel van concurrentie te huldigen.

Wij hebben intusschen nog een groot deel van het werk van den Heer $\nabla$. te goed, namelijk zijn IVe Hoofdstuk (hl. 333-605): „Onderzoek vaar de waarde der argumenten, onlangs in de Tweede "Kamer der Staten-Generaal ten voordeele van het behoud van het "monopolie der Nederlandsche Bank aangevoerd." Na eene duidelijke en beknopte uiteenzetting van de wording van het monopolie, hetwelk de regering in 1814 en 1838 minder uitdrukkelijk verleende, dan de wetgevende magt in 1863, volgt eene breede wederlegging van de betoogen der Heeren Betz en van Bosse, bij de belangrijke discussiën over de bankwet gehouden, vooral van de redevoering des Ministers op 16 November 1863. Dit gedeelte van het boek vooral is con amore en met veel talent geschreven; maar hoe uitnemend de heer $V$. zijue zaak ook bepleite, het is een pleidooi na het vonnis! - Ref. zal zich dus van elke analyse onthouden.

In de allerlaatste bladzijden betreedt de schrijver weder geheel het terrein der actualiteit. Hij beschouwt de zaak der bankvrijheid in Nederland niet als voor een 25jarig tijdperk verloren, en wenscht, met het oog op art. 1 der Bankwet, dat de slagboom der concur. rentie zoo spoedig mogelijk worde opengesteld.

In dezen zin komt hij op tegeu de beoordeeling onzer Bankwet in het Journal des scononistes, welke auders zijn gevoelen geheel uitdrukt: „La nouvelle loi banquière reste un fâcheux anachronisme, „puisqu'elle consacre le monopole à une époque, où tout tend vers „la liberté économique et dans un pays, qui a toujours su faire „le meilleur emploi de cette liberté." Hij wenscht dat spoedig eene bijzondere wet voor eene nieuwe circulatiebank worde voorgedragen en aangenomen: $1^{\circ}$. opdat Nederland langs dien weg in het genot der voordeelen gerake, die de vrije banken in Schotland en Zwitserland in zóó ruime mate aan de bevolking dier landen hebben verschaft; $2^{\circ}$. omdat de Ned. Bank, zoo zij op een 25jarig monopolie rekent, niet voor alle deelen des lands nuttig zal werken, dan 
voor zooverre zij dit in haar eigen belang zal oordeelen; immers op de werking der Bijbank en agentschappen valt z. i. weinig to rekenen; als afsehrikkend voorbeeld wijst hij op de Bank van Frankrijk, die, sedert de departementale banken zijn opgeheven (in 1848), huiverig is, zelfs in vrij groote steden, succursales op te rigten, ja dit aan de Savoysche departementen zou hebben geweigerd. $\left(^{*}\right)$

Hoe groote waarde wij ook aan het eerste dezer argumenten hechten, hoezeer wij met den schr. overeenstemmen, dat alleen met het stelsel van concurrentie de bank- en crediet-instellingen al het nut kumnen voortbrengen, waarvoor zij vatbaar zijn, zoo vinden wij toch juist in de gezigtspunten, die het tweede argument opent, eene reden om niet met zijne conclusie in te stemmen.

De Ned. Bankwet heeft het bankbillet, hetwelk zij alleen als circulatiemiddel heeft beschouwd, in handen der Ned. Bank gemonopoliseerd; daarentegen heeft zij die instelling tot kassier van den Staat gemaakt, in vele opzigten onder voogdij gesteld, en haar bepaald drieërlei operatiën ontzegd: het hypothecair crediet, het blanco crediet, en deposito's met rente. Deze vakken zijn aan de vrije concurrentie overgelaten, zonder dat deze zelfs de geprivilegiëerde instelling dáár ontmoet; andere takken van het bankiersbedrijf mag ieder, zoo hij kan, in mededinging met de Bank uitoefenen. Het noodwendige gevolg hiervan moet en zai zijn, bij eene kundige en bekwame directie (zooals die welke thans de Ned. Bank bestuurt), voortdurende af hankelijkheid van alle bankiers- en bank.instellingen van de Ned. Bank, voor zooveel hare disconto's en haar metaalhandel betreft, eene afhankelijkheid, waartegen het vertrouwen op grooto veiligheid overstaat; buiten de aldus afgeperkte grenzen, vrijheid van beweging.

Zoo ziet men sedert twee jaren niet alleen het getal crediet- en bankinstellingen in Nederland aanmerkelijk toenemen, maar de geheele kassierderij geheel van aard veranderen en overgaan in eene soort van spaar- en disconto-banken, die aan het productief maken van anders stilliggende kapitalen zeer bevorderlijk zullen zijn. Tevens moet men letten op de eischen die de wet aan de Ned. Bank heeft gesteld ten opzigté van de oprigting van de Bijbank en agentschappen. Die eischen konden alleen aan eene monopolie-bank worden gedaan, en, zou ieder voorstander der bankprijheid de voorkeur

(*) Zeer onlangs zijn, bij transactie, over.het bekende privilegie, de regten der Bank van Savoge door de Bank van Frankrijk afgekocht voor fr. 4,000,000, en is daarbij de oprigting van succursales te Annecy en te Chambéry bedongen.

Econ. 1865. 
hebben gegeven aan onafhankelijke, locale of provinciale banken, hij mag niet vergeten, dat de Bijbank en agentschappen nu eenmaal zijn opgerigt. Immers in dit opzigt heeft de Directie de ongunstige verwachting van den heer Verloren beschaamd; reeds den 18 Mei 1864 werd het Reglement voor de inrigting en den werkkring der Bijbank en der agentschappen vastgesteld (den 4 Junij bij Kon.Besluit goedgekeurd); daarbij zijn de bevoegdheden van het Rotterdamsche Bijbank-bestuur, in zijne handellingen tegenover particulieren, ruim gesteld, en nog in den loop van hetzelfde jaar hebben 's Hertogenbosch, Arnhem, Dordrecht, Alkmaar, Middelburg, Utrecht, Leeuwarden, Zwolle, Almelo, Groningen, Meppel en Maastricht, ieder zijnen agent der Ned. Bank, met 2 of 3 adviseurs bijgestaan, op zijn respectief kantoor zien zitten.

Ex is dus zelfs meer geschied, dan art. 5 der wet vorderde, namelijk één agentschap in iedere provincie op te rigten.

Ware het nu wel raadzaam, zeer kort nadat de zaken deze plooi hebben genomen, en vóór dat iemand kan beoordeelen, welke diensten de Bank naar hare tegenwoordige inrigting aan handel en nijverheid zal bewijzen, een concurrent op haar af te zenden? Wij gelooven niet, dat de Ned. regering en vertegenwoordiging, zelfs niet die minderheid, die eene meer liberale Bankwet had verlangd, daartoe zouden willen overgaan; wij zouden het ook niet wenschelijk achten, vóórdat de ondervinding van eenige jaren, in het volle licht der publiciteit opgedaan, hebbe doen zien, in welke opzigten de Bankwet ongunstig zal werken. Tot zóólang geniete de onbesprokene Ned. Bank, "wier soliditeit tot een spreekwoord is geworden", haar genoegelijk monopolie van renteloos crediet in den geliefkoosden vorm van bankbilletten, en zegge met het oog op de stormen, die elders, zoowel aan de gemonopoliseerde maar niet onbesprokene banken (b. $v$. te Weenen en te Madrid), als hare vrije zusters (b. $\nabla$. in Amerika) over het hoofd gaan, en die waarmede de crédits fonciers en mobiliers te kampen hebben, den ouden dichter na:

"Saave, mari magno turbantibus aequora ventis, „E terra magnum alterius spectare laborem; "Non, quia verari quemquam est iucunda volnptas, „Sed, quibus ipse malis careas, quis cernere suave est." (")

(*) Lucretius, de rer. nat., 1. II. pr. "Hoe zoet is 't, als de storm de wilde golven jaagt, "Heel veilig op het strand, den schępling na te staren; "Niet dat wij juichen om zijn angsten en gevaren, "Maar zoet is eigen rust, waar zorg een ander plaagt." 
Letten wij op het weinige, dat van buiten af, uit de ondervinding van nog geen jaar sedert de invoering der Bankwet (1 April 1864) kan worden opgemaakt, dan zijn wij geneigd te gelooven, dat, in dit korte tijdperk, die of dergelijke gedachte het rigtsnoer der Bankdirectie is geweest. En dewijl in dit tijdperk juist eene handels- of geld-krisis is voorgekomen, en de houding der Bank daarbij teregt de aandacht getrokken heeft, laten wij hier de cijfers van hare operatiën volgen.

Den 18 April 1864 werd bij koninklijk Besluit, ter uitvoering van art. 16 der Bankwet, bepaald, dat het gezamenlijk bedrag der omloopende bankbilletten, bank-assignatiën en rekening-courantsaldo's steeds voor $\frac{2}{5}$ zal moeten zijn gedekt door munt en muntmateriaal (goud en zilver); uit de sedert openbaar gemaakte weekstaten hebben wij, naar de eerste van elke maand, deze verhouding en het opererend kapitaal berekend $\left({ }^{*}\right)$.

\begin{tabular}{|c|c|c|c|c|c|c|c|}
\hline 1864. & $\stackrel{a}{\text { Munt enz. }}$ & $\begin{array}{c}b \\
\text { Bankbill. }\end{array}$ & $\begin{array}{l}c \\
\text { Rek. cour. } \\
\text { saldo's. }\end{array}$ & $\begin{array}{c}d \\
\text { Bank- } \\
\text { assign. }\end{array}$ & $\begin{array}{c}e \\
\text { Totaal } \\
b, c, d .\end{array}$ & $\underset{\substack{f \\
\text { Opererend } \\
\text { kapitaal. }}}{f}$ & $\begin{array}{l}g \\
\text { Verhoud. } \\
a \text { tot e. }\end{array}$ \\
\hline Mei & 87313 & 116401 & 31558 & - & 147959 & 76646 & 0,590 \\
\hline Junij 6 & 84130 & 111009 & 31954 & - & 142963 & 74833 & 0,588 \\
\hline Julij & 79775 & 105158 & 29294 & - & 134452 & 70677 & 0,593 \\
\hline Aug. & 78942 & 106521 & 27740 & - & 134261 & 71319 & 0,587 \\
\hline Sept. & 73089 & 99898 & 33559 & - & 133457 & 76368 & 0,547 \\
\hline Oct. 3 & 70002 & 100653 & 29264 & - & 129917 & 75915 & 0,544 \\
\hline Nov. 7 & 73697 & 104446 & 37077 & - & 141523 & 83826 & 0,520 \\
\hline $\begin{array}{c}\text { Dec. 5 } \\
1865 .\end{array}$ & 75337 & $\cdot 98949$ & 38667 & - & 137616 & 78279 & 0,540 \\
\hline Jan. 2 & 77972 & 97780 & 38667 & 4 & $1364 \Xi 1$ & 74479 & 0,570 \\
\hline Febr. 6 & 83668 & 102427 & 30963 & 3 & 133393 & 65725 & 0,627 \\
\hline Mrt. 6 & 86963 & 102685 & 27399 & 7 & 130091 & 59128 & 0,668 \\
\hline
\end{tabular}

Het gemiddelde cijfer van de laatste kolom over de elf maanden is 0.579 , terwijl het genoemde kon. Besluit vergunde tot 0,4 af te dalen. In het boekjaar 1863/64 was die verhouding 0,699 geweest.

Tusschen den vloed en de ebbe die men in de kolommen $f$ en $g$ zal opmerken, en de koersen van het disconto en de beleening der Bank, die in dit tijdperk sterk fluctueerden, bestaat een blijkbaar verband.

(*) De cijfers drakken duizendtallen van guldens uit. Het kapitaal der Bank is, 200 als men weet, $f 16000000$; het reservefonds $f 2400000$; daar dit bijna geheel belegd is, kan het buiten rekening worden gelaten bij de bepaling vad het opererend kapitaal. 
Van April tot $20 \mathrm{Junij}$ was het wisseldisconto $(*) 5$, beleening op effecten $(\dagger) 5$

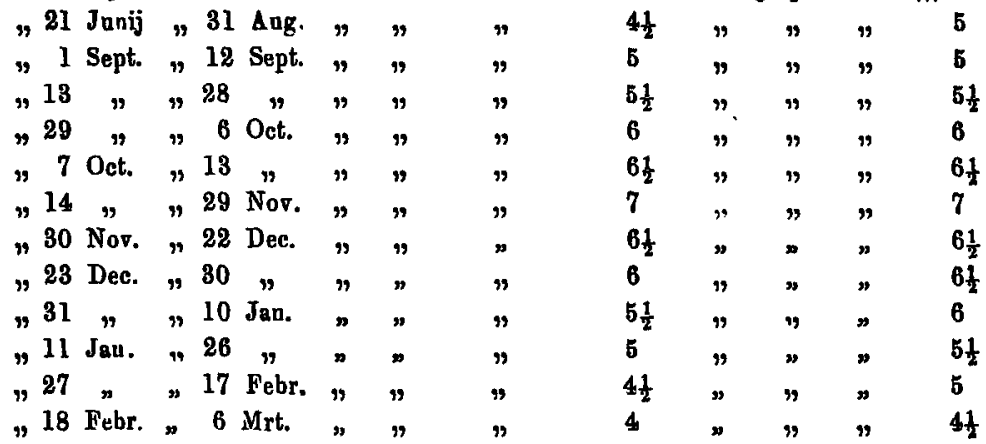

Vergelijkt men deze koersen met die van 1857 en 1858 , (o. a. te vinden bij Vissering, de Ned. Bank enz. in de Gids, 1863, II, bl. 216) dan riet men dat de krisis van 1864 die van genoemde jaren niet heeft geërenaard. Ook is de Nederlandsche Bank, tijdens het ergste der krisis, steeds beneden de Londensche en $\mathrm{Pa}$ rijsche koersen gebleven. Evenwel zijn destijds door haar, hoezeer met gematigdheid, beperkende maatregelen genomen, althans waarschuwingen gegeven, met opzigt tot het bedrag en den omloopstijd der te disconteren traites.

Wij herinneren ons hierbij, dat in de meer besproken discussie in de Tweede Kamer ( $\operatorname{van}$ Nov. 1863) de heer Cool ten voordeele der Bankwet het argument bezigde, dat ,in gewone tijden bij par"ticulieren het geld wel eens goedkooper te krijgen is, dan bij de "Bank; maar in tijden van geldnood, wanneer de rentestandaard "hoog is, gaan, zoo als men het wel eens uitdrukt, de geldmannen „op de kist zitten en dan kan men bij de Nederlandsche Bank toch "geld krijgen en geholpen worden. Dat is indedaad een groot voor"deel." Waarop de heer van Voorthuijsen aanmerkte: „De geachte "afgeraardigde bezigde nog een argument ten voordeele dezer "wet, zeggende dat in tijden van krisis de geldmannen te Am"sterdam op de geldkist gaan zitten. Dit toch zou de Directie "der Ned. Bank niet doen. Het ware inderdaad van de leden "dier Directie niet te verwachten. Maar wat zouden deze dan "doen? Zij zouden eenvoudig het disconto verhoogen, en nu meen $n$ ik te mogen betwijfelen, of die maatregel wel in de gevolgen voor "hen, die geld behoeven, een zoo groot verschil zoude zijn." - Deze

(*) Het promessen-disconto was steeds $\frac{f}{2} \mathrm{pCt}$. hooger.

( $\dagger$ ) De beleening op goederen was in den regel oven hoog, op enkele dagen $\frac{1}{2} \mathrm{pCt}$. hooger; de beleening op goud en zilver bleef $1 \mathrm{pCt}$. 
hoogst eenvoudige teregtwijzing werd destijds als eene aardigheid van den geestigen spreker beschouwd. Men kon er echter meer in vinden. De spreker raakte hier werkelijk aan eene teedere snaar.

Blijkens de warme polemiek der laatste weken over het Bankwezen in Frankrijk, uitgelokt vooral door den hoer I. Pereire, wordt dáár aan de geprivilegiëerde Bank de eisch gesteld, dat zij, als prijs voor haar monopolie, het publiek steeds ten dienste sta met een disconto, dat 4 of hoogstens $5 \mathrm{pCt}$. niet te boven ga. Opmerkelijk stemt deze eisch overeen met een bekend woord van Napoleon I, die in 1810 aan zijn Minister van financiën schreef, dat het Bestuur der Bank van Frankrijk in zijne vergaderzaal met vergulde letteren aan den wand moest laten schrijven: „Quel est le but de la Banque "de France? D'escompter les crédits de toutes les maisons de commerce "à quatre pour cent." De eisch, aldus geformuleerd, is overdreven, omdat hij te absoluut is gesteld; ook hetgeen de Heer Pereire eischt, schijnt onbillijk. Maar wat heeft men te denken van de daartegenoverstaande stelling van den Heer de Germiny, den gouverneur der Bank (in 1864): dat eene geprivilegiëerde bank aan hare bestemming voldoet, wanneer zij kapitaal beschikbaar stelt voor den handel en de nijverheid "zà quelque prix que ce soit"? Is er geen weg te vinden om geleidelijk de weldaden van het crediet nog meer toegankelijk te maken voor hen die het voor goede zaken behoeven, zonder dien despotieken dwang, dien men in Frankrijk zoo ligt geneigd is onbedacht, ook met goede bedoelingen, in te roepen ? - De behandeling dezer zijde van de bankquestie, al ware het niet bepaald met het oog op de Ned. Bank en Bankwet, zoû uitnemend zijn toevertrouwd an iemand van zóóveel studie en zóó verlichte oeconomische begrippen als de Heer Verloren.

Amsterdain, 19 Maart 1865.

J. HEEMSKERK Az. 